\title{
Swelling of Copper Powders during Sintering of Heat Pipes in Hydrogen-Containing Atmospheres
}

\author{
Yueh-Ju Lin*1 and Kuen-Shyang Hwang*2 \\ Department of Materials Science and Engineering, National Taiwan University, \\ 1, Roosevelt Rd., Sec. 4, Taipei 106, Taiwan, R. O. China
}

Swelling of copper powders often occurs during sintering of heat pipes and causes problems in removing core rods from the fixture. To address this problem, this study examines the effects of sintering atmospheres $\left(\mathrm{H}_{2}, \mathrm{~N}_{2}-10 \% \mathrm{H}_{2}, \mathrm{~N}_{2}\right.$, and vacuum) and oxygen content in copper powders on the density and dimensional changes of loose-powder-sintered copper compacts. The results show that serious powder cracking occurs when high oxygen content is present in the as-received powder and when the sintering atmosphere contains hydrogen due to the hydrogen-oxygen reaction forming water vapors. The dilatometer curve indicates that such reaction starts between 673 and $723 \mathrm{~K}$. Comparison of the pycnometer density and Archimedes' density of sintered compacts suggests that the swelling is mainly caused by cracking of the powder, and that the plastic deformation caused by the expansion of trapped gas in isolated pores plays a minor role. To prevent such cracking and swelling, copper powders with low oxygen content should be used, and the sintering should be carried out in an atmosphere with low hydrogen content or under vacuum or inert gas atmosphere. [doi:10.2320/matertrans.M2010151]

(Received April 26, 2010; Accepted September 10, 2010; Published November 3, 2010)

Keywords: copper, hydrogen atmosphere, sintering, swelling, heat pipe

\section{Introduction}

Heat pipes with sintered porous structures have been used widely to resolve the thermal management problems of electronic devices, such as notebook computers, light emitting diodes, and fuel cells. ${ }^{1,2)}$ To provide effective heat dissipation, the water at one end of the sealed heat pipe, which is under partial vacuum, evaporates into vapor that cools the hot device by using the latent heat. The water vapor then passes through the hollow channel in the center of the heat pipe to the cold end, where the water vapor condenses. This condensed water is then transported back to the hot evaporator section by the capillary pressure in porous copper wicks, which are sinter-bonded to the outer copper tubing. ${ }^{1)}$

One of the processes used to fabricate such heat pipes is loose-powder-sintering. As illustrated in Fig. 1, copper powders are loaded into the space between the surfacetreated stainless steel core rod and the outer tubing, which is made of oxygen-free copper. The assembly is then sintered in a mixed hydrogen-nitrogen atmosphere. After sintering, copper powders are bonded to each other and to the copper tubing, but not to the surface-treated core rod. The core rod is then removed, leaving a hollow channel in the heat pipe. However, industrial practices have suffered occasionally the problem that the cored rod is jammed due to the swelling of the surrounding copper powders during sintering. Separations between copper wicks and copper tubing and also among copper powders, have also been noticed when heat pipes are bent in order to fit into the allocated space in the electronic devices. Lin and Hwang demonstrated in a heat pipe study that copper powders with larger amounts of oxygen incurred serious swelling, and they also observed cracking of powders when sintering was carried out in hydrogen. ${ }^{3)}$ However, in that paper, the details of the

\footnotetext{
${ }^{* 1}$ Graduate Student, National Taiwan University

${ }^{* 2}$ Corresponding author, E-mail: kshwang@ccms.ntu.edu.tw
}

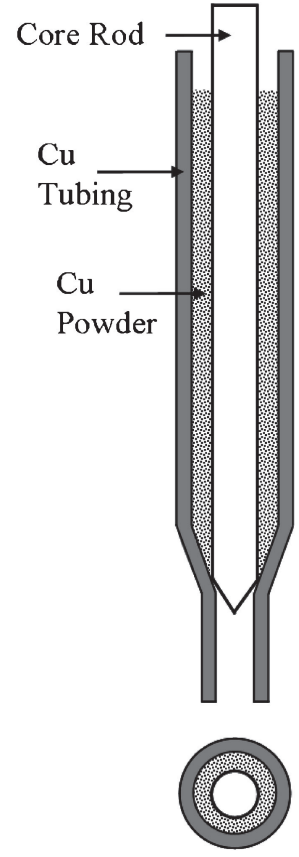

Fig. 1 The schematics of the sintering fixture used for fabricating copper heat pipes.

phenomena and mechanisms of formation of the swelling and cracking were not discussed.

For wrought copper prepared with conventional ingot metallurgy, it has been reported that swelling and embrittlement occur when copper is in contact with hydrogen at high temperatures. ${ }^{4-8)}$ The reason is that hydrogen diffuses rapidly into copper and reacts with the residual copper oxide or the dissolved oxygen in the copper forming water vapor. The water vapor thus formed cannot escape to the ambience along the same path which enabled hydrogen to diffuse through the copper, due to its large molecular size. With the high equilibrium gas pressure ratio of $\mathrm{H}_{2} \mathrm{O} / \mathrm{H}_{2}$, the resulting steam 
accumulates and builds high pressures within the copper. The high-pressure steam causes the copper to expand, and the volume of the copper increases as the degree of the prior plastic deformation of the copper increases. With the presence of the reacted gas, the copper also becomes brittle.

The embrittlement of copper has also been observed in electroless copper films on printed circuit boards. However, the embrittlement mechanism is different. Nakahara reported that small hydrogen bubbles $(\sim 0.2 \mu \mathrm{m})$ with high pressure were trapped at grain boundaries, causing embrittlement. Low-temperature annealing at $423 \mathrm{~K}$ for $86.4 \mathrm{ks}$ resolves this problem by causing out-diffusion of the hydrogen. ${ }^{9)}$ However, no data on the dimensional changes caused by hydrogen bubbles were reported due to the small thickness of the copper film.

Several studies on swelling and hydrogen embrittlement of powder metal compacts have also been reported. One reported source of swelling is the air entrapped in pores, closed-off during compaction, which expands during the subsequent heating and sintering. ${ }^{4,10,11)}$ The other reported source of swelling is the gas formed during sintering in hydrogen-containing atmospheres. The reaction gas that is trapped in the matrix has been identified as water vapor by Ito and Hayashi, who used a quadrupole mass spectrometer during the in-situ fracture test. ${ }^{12)}$ This water vapor pressure is high enough to exceed the surface stress $(\sigma=2 \gamma / \mathrm{r}$, where $\gamma$ is the surface tension and $\mathrm{r}$ is the radius of the closed pore), which is the driving force for the pore shrinkage during sintering. As a result, swelling of sintered compacts occurs, particularly when the compact has a high oxygen content and a high green density with large amounts of trapped air. ${ }^{11,13)}$ However, when compacts with low green densities were sintered, little expansion was observed and shrinkage still occurred, in contrast to the swelling of porous copper wicks described in some studies. ${ }^{12,13)}$ The explanation was that low green density compacts have high surface area and high sinterability, and the resulting shrinkage can negate the swelling of trapped water vapor. Another reason is that porous compacts provide many interconnected pores to facilitate the outward permeation of the water vapor during sintering.

Another factor that adds complications to the explanation of swelling is the particle size of the copper powder. Fine powders with large amounts of surface area have a high driving force for sintering and the resulting shrinkage can offset the growth of copper compacts. In addition, fine powders have short transport distance for the out-diffusing gas molecules and could thus decrease the pressure of the trapped gas. Hayashi et al. reported the densities of compacts prepared with fine copper powders with a mean diameter of $0.05 \mu \mathrm{m}$ and $5-11 \mu \mathrm{m}$. All compacts obtained high densities and large amounts of shrinkage even when the green density was low. But the final sintered density could reach only $93-$ $96 \%$ because the high pressure water vapor inside the isolated pore inhibited further densification. ${ }^{11,14)}$ To address this problem, elements with high affinity to oxygen, such as chromium and iron, have been added to form stable oxides and inhibit the steam formation. ${ }^{11,13,15)}$ Vacuum sintering was also shown by Hayashi et al. to be effective in achieving high sintered densities. ${ }^{16)}$
As described above, the particle size of the $\mathrm{Cu}$ powder, sintering atmosphere, and green density are all important factors in determining the dimensional change and ductility of sintered copper. However, little information has been reported on the related problems in heat pipe practices, which use coarse copper powder and low green density. Moreover, we are interested in separating the mechanisms of swelling and hydrogen embrittlement in heat pipes; this combination of phenomena could be caused by the high pressure water vapor or hydrogen bubbles. Thus, the objective of this study was to examine the effects of oxygen content in the copper powder and sintering atmospheres on the dimensional changes of copper powders during loose-powder-sintering, which is generally used in fabricating heat pipes. Two spherical powders with different oxygen contents and four different atmospheres, $\mathrm{H}_{2}, \mathrm{~N}_{2}-10 \% \mathrm{H}_{2}, \mathrm{~N}_{2}$, and vacuum, were used.

\section{Experimental Procedure}

Gas atomized copper powders, which were spherical in shape, were used in this study in order to eliminate the complexity caused by variations in the powder shape, such as mechanical locking among powders with irregular shape. Since copper powders used for heat pipes are usually about $100 \mu \mathrm{m}$, two different powders with mean particle sizes of 55.7 and $147.3 \mu \mathrm{m}$, one above and one below $100 \mu \mathrm{m}$, were chosen and were designated as fine and coarse powders, respectively. These two powders were selected also because they contained different amounts of oxygen so that the effect of oxygen content on swelling during sintering could be examined. Table 1 shows that the fine powder had a slightly higher apparent density, tap density, and low oxygen content of 0.193 mass \%, which is contradictory to most findings, which show that finer powders have larger surface area and thus more interparticle friction, lower apparent density, lower tap density, and high oxygen content. The reason is probably that the coarse powders used in this study contained internal pores and high amounts of oxygen, which is closely related to the copper scraps used for gas atomization. The morphologies and cross-sections of the coarse and fine powders are shown in Fig. 2 and Fig. 3, respectively.

Table 1 The characteristics of the coarse and fine copper powders used in this study.

\begin{tabular}{lcc}
\hline \multicolumn{1}{c}{ Characteristics } & Coarse & Fine \\
\hline Designation & $83 \mathrm{~A}$ & $153 \mathrm{~A}$ \\
Apparent Density, $\mathrm{kg} / \mathrm{m}^{3}$ & $4.91 \times 10^{3}$ & $5.12 \times 10^{3}$ \\
Tap Density, $\mathrm{kg} / \mathrm{m}^{3}$ & $5.55 \times 10^{3}$ & $5.88 \times 10^{3}$ \\
True Density, $\mathrm{kg} / \mathrm{m}^{3}$ & $8.55 \times 10^{3}$ & $8.75 \times 10^{3}$ \\
(Pycnometer) & & \\
Particle Size, $\mu \mathrm{m}$ & & \\
(Laser Scattering Method) & 108.2 & 37.3 \\
$\quad \mathrm{D}_{10}$ & 147.3 & 55.7 \\
$\quad \mathrm{D}_{50}$ & 199.7 & 83.6 \\
$\quad \mathrm{D}_{90}$ & 0.471 & 0.193 \\
Oxygen Content, mass\% & 0.002 & 0.001 \\
Nitrogen Content, mass\% & ACu Powder & ACu Powder \\
Supplier & & \\
\hline
\end{tabular}


(a)



(b)

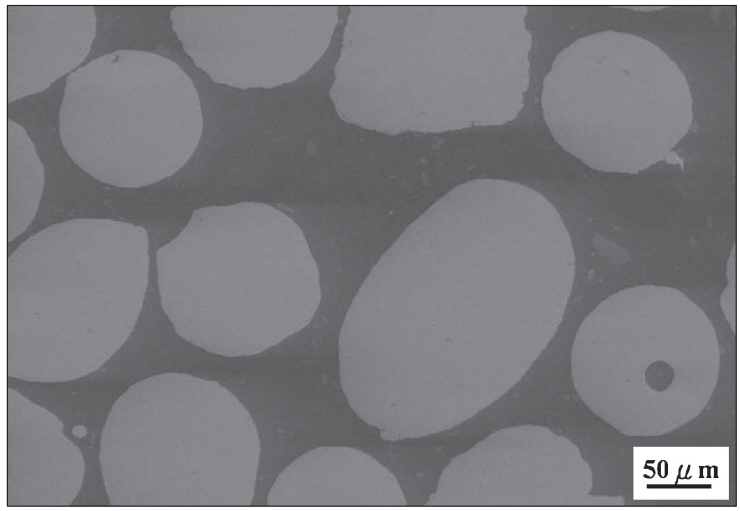

Fig. 2 The (a) morphology and (b) cross-section of the coarse copper powder used in this study.

Loose-powder-sintering was used in this study to simulate the process of making heat pipes. Copper powders were poured into a graphite mold cavity $13 \mathrm{~mm}$ in diameter and $14 \mathrm{~mm}$ deep and tapped for $60 \mathrm{~s}$. The Cu-powder-filled graphite mold was then heated at $0.167 \mathrm{~K} / \mathrm{s}$ to $1323 \mathrm{~K}$ and held at that temperature for $3.6 \mathrm{ks}$ in pure $\mathrm{H}_{2}, \mathrm{~N}_{2}-10 \% \mathrm{H}_{2}, \mathrm{~N}_{2}$, or vacuum $(1.33 \mathrm{~Pa})$. To analyze the sintering behavior, a vertical type of dilatometer (TMA, SETSYS TMA16/18, STERAM Co., Calurie, France) was employed to monitor the in-situ dimensional change during sintering. To make dilatometer specimens, the copper powder was loaded into a graphite cavity, $6 \mathrm{~mm}$ in diameter and $5 \mathrm{~mm}$ deep, and an alumina pushrod was then placed on the top. The loading on the powder was adjusted to $1 \mathrm{~g}$ only in order to alleviate the hot pressing effect during the test.

The sintered density was measured using the Archimedes' method with oil impregnation techniques (ASTM standard B328). To understand the swelling mechanism, the true density of the sintered skeleton was compared to the sintered density (Archimedes' density). The true density was measured using a helium pycnometer (Ultrapycnometer-1000, Quantachrome Co., Ithaca, NY, USA) (ASTM standard D2638), with which the product volume measured includes isolated pores, but not cracks or open pores, for they can be penetrated by the small helium molecules. The oxygen contents of powders and sintered compacts were measured utilizing a LECO N/O analyzer (TC-136, LECO Co., St. Joseph, Michigan, USA). To observe the swelling and cracking, microstructures of the as-received powder and sintered compact were compared using a scanning electron (a)

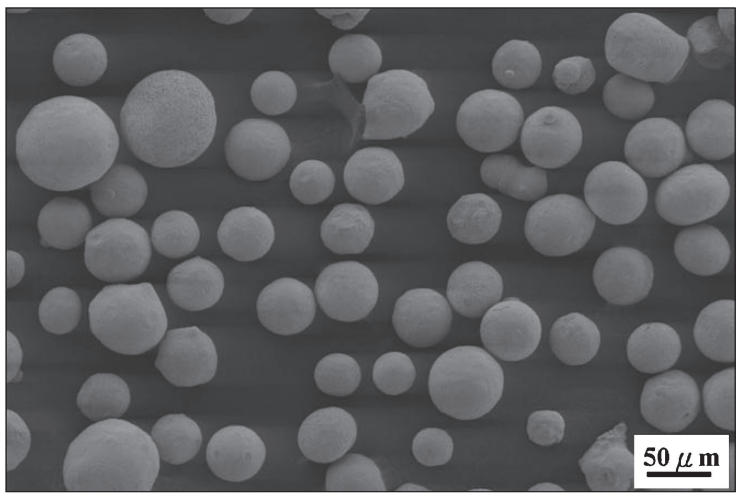

(b)

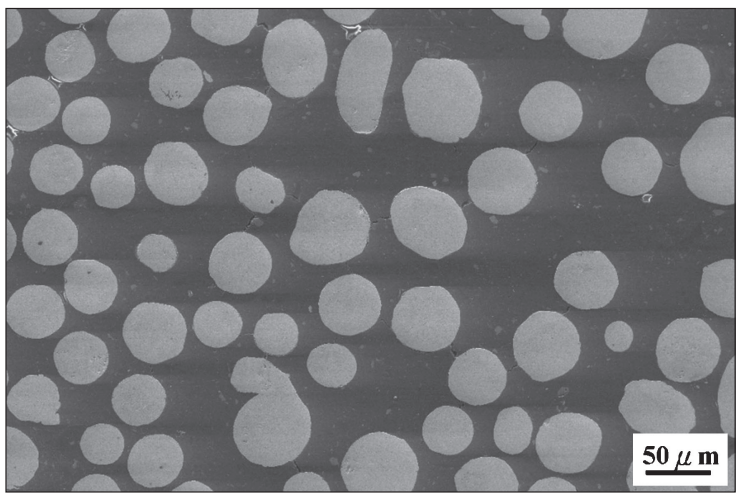

Fig. 3 The (a) morphology and (b) cross-section of the fine copper powder used in this study.

microscope (Field Emission SEM, LEO 1530, LEO Electron Microscopy Co., Cambridge, England).

\section{Results}

\subsection{Density}

In industrial practices, most heat pipe assemblies are sintered in a reducing atmosphere so that the oxide layer on copper powder surfaces can be reduced and good interparticle bonding can be obtained. ${ }^{3,17,18)}$ However, Table 2 shows that coarse powders sintered in pure hydrogen had the lowest density of $\left(4.98 \times 10^{3} \mathrm{~kg} / \mathrm{m}^{3}\right)$ followed by $\mathrm{N}_{2}-10 \% \mathrm{H}_{2}$ $\left(5.26 \times 10^{3} \mathrm{~kg} / \mathrm{m}^{3}\right)$, while nitrogen and vacuum produced the highest density $\left(5.61 \times 10^{3} \mathrm{~kg} / \mathrm{m}^{3}\right)$. Compared to the tap density of the as-received coarse copper powder, $5.55 \times$ $10^{3} \mathrm{~kg} / \mathrm{m}^{3}$, it is clear that swelling occurred when hydrogencontaining atmospheres were used, whereas densification occurred when compacts were sintered in nitrogen and vacuum. When fine powders were used, all atmospheres gave similar densities, between 6.08 and $6.12 \times 10^{3} \mathrm{~kg} / \mathrm{m}^{3}$, all of which were above the tap density of the fine powder, $5.88 \times 10^{3} \mathrm{~kg} / \mathrm{m}^{3}$. This indicated that swelling either did not occur or was not significant enough to offset the densification caused by the sintering of fine powders.

Since the final density and dimensional change are determined by two opposing factors, i.e., the shrinkage between copper powders due to sintering and the swelling of individual copper powders due to gas reaction, the pycnometer densities of sintered compacts were measured to determine the fraction of the powder swelling. Table 2 
Table 2 Sintered density, weight loss, and oxygen content of sintered Cu compacts prepared with coarse powders and fine powders.

\begin{tabular}{|c|c|c|c|c|c|c|c|c|c|c|}
\hline \multirow[t]{2}{*}{$\begin{array}{l}\text { Sintering } \\
\text { atmosphere }\end{array}$} & \multicolumn{2}{|c|}{$\begin{array}{l}\text { Sintered Density, } \\
\mathrm{kg} / \mathrm{m}^{3} \\
(\%)\end{array}$} & \multicolumn{2}{|c|}{$\begin{array}{l}\text { Pycnometer Density, } \\
\qquad\left(\mathrm{kg} / \mathrm{m}^{3}\right)\end{array}$} & \multicolumn{2}{|c|}{$\begin{array}{l}\text { Weight Loss, } \\
\quad(\text { mass } \%)\end{array}$} & \multicolumn{2}{|c|}{$\begin{array}{l}\text { Oxygen Content, } \\
\text { (mass } \%)\end{array}$} & \multicolumn{2}{|c|}{$\begin{array}{l}\text { Nitrogen Content, } \\
(\text { mass } \%)\end{array}$} \\
\hline & Coarse & Fine & Coarse & Fine & Coarse & Fine & Coarse & Fine & Coarse & Fine \\
\hline $100 \% \mathrm{H}_{2}$ & $\begin{array}{c}4.98 \times 10^{3} \\
(55.5)\end{array}$ & $\begin{array}{l}6.11 \times 10^{3} \\
(68.2)\end{array}$ & $8.43 \times 10^{3}$ & $8.79 \times 10^{3}$ & 0.47 & 0.21 & 0.005 & 0.006 & 0.005 & 0.004 \\
\hline $10 \% \mathrm{H}_{2}$ & $\begin{array}{l}5.26 \times 10^{3} \\
\quad(58.7)\end{array}$ & $\begin{array}{c}6.08 \times 10^{3} \\
(67.9)\end{array}$ & $8.48 \times 10^{3}$ & $8.77 \times 10^{3}$ & 0.42 & 0.19 & 0.008 & 0.007 & 0.004 & 0.003 \\
\hline $\mathrm{N}_{2}$ & $\begin{array}{l}5.61 \times 10^{3} \\
(62.6)\end{array}$ & $\begin{array}{c}6.12 \times 10^{3} \\
(68.3)\end{array}$ & $8.71 \times 10^{3}$ & $8.81 \times 10^{3}$ & 0.48 & 0.26 & 0.006 & 0.005 & 0.006 & 0.005 \\
\hline Vacuum & $\begin{array}{l}5.61 \times 10^{3} \\
(62.6)\end{array}$ & $\begin{array}{c}6.09 \times 10^{3} \\
(68.0)\end{array}$ & $8.70 \times 10^{3}$ & $8.78 \times 10^{3}$ & 0.52 & 0.24 & 0.002 & 0.005 & 0.002 & 0.002 \\
\hline
\end{tabular}

shows that the pycnometer densities of the coarse powders sintered in hydrogen and $\mathrm{N}_{2}+10 \% \mathrm{H}_{2}$ were $8.43 \times 10^{3}$ and $8.48 \times 10^{3} \mathrm{~kg} / \mathrm{m}^{3}$, respectively, which were lower than the $8.55 \times 10^{3} \mathrm{~kg} / \mathrm{m}^{3}$ of the as-received powder. In comparison, the pycnometer densities of coarse copper powders sintered in nitrogen and vacuum increased slightly, from the $8.55 \times$ $10^{3} \mathrm{~kg} / \mathrm{m}^{3}$ of the as-received powder to $8.71 \times 10^{3}$ and $8.70 \times 10^{3} \mathrm{~kg} / \mathrm{m}^{3}$, respectively. When fine powder was used, the pycnometer densities of powder compacts sintered in all atmospheres were between $8.77 \times 10^{3}$ and $8.81 \times 10^{3}$ $\mathrm{kg} / \mathrm{m}^{3}$, slightly higher than the $8.75 \times 10^{3} \mathrm{~kg} / \mathrm{m}^{3}$ in the asreceived condition.

Comparison of the pycnometer densities illuminated how compacts expanded during sintering. Using coarse copper powders as an example, the pycnometer density decreased from $8.55 \times 10^{3} \mathrm{~kg} / \mathrm{m}^{3}$ to $8.43 \times 10^{3} \mathrm{~kg} / \mathrm{m}^{3}$ after sintering in hydrogen. This means that there was a $1.4 \%$ volume expansion in the powder itself. However, the sintered density measured with the Archimedes'method decreased from $5.55 \times 10^{3} \mathrm{~kg} / \mathrm{m}^{3}$ of the tap density to $4.98 \times 10^{3} \mathrm{~kg} / \mathrm{m}^{3}$ after sintering, which is equivalent to an $11.4 \%$ increase in volume. This suggests that other factors contribute to the swelling of sintered copper compacts, not just the expansion of gases in internal pores.

\subsection{Oxygen content}

Table 2 shows that the copper compacts sintered in hydrogen and $\mathrm{N}_{2}-10 \% \mathrm{H}_{2}$, contained very little oxygen, less than 0.01 mass $\%$, much lower than the 0.471 mass $\%$ and 0.193 mass $\%$ in the as-received coarse and fine powder, respectively. When sintered in nitrogen and vacuum, reduction still occurred, probably due to the low partial pressure of oxygen in the atmosphere, and the oxygen content was also lower than 0.01 mass\%. This decrease in oxygen content is one of the reasons why the pycnometer density of the sintered fine powders increased, as described in the previous section. The nitrogen contents of sintered copper powders were also measured and were not much different from those in asreceived powders.

\subsection{Dilatometry analysis}

The previous results on pycnometer density and oxygen content indicate that coarse copper powders with high oxygen content will form water vapor, causing expansion, when sintered in hydrogen-containing atmospheres. But the

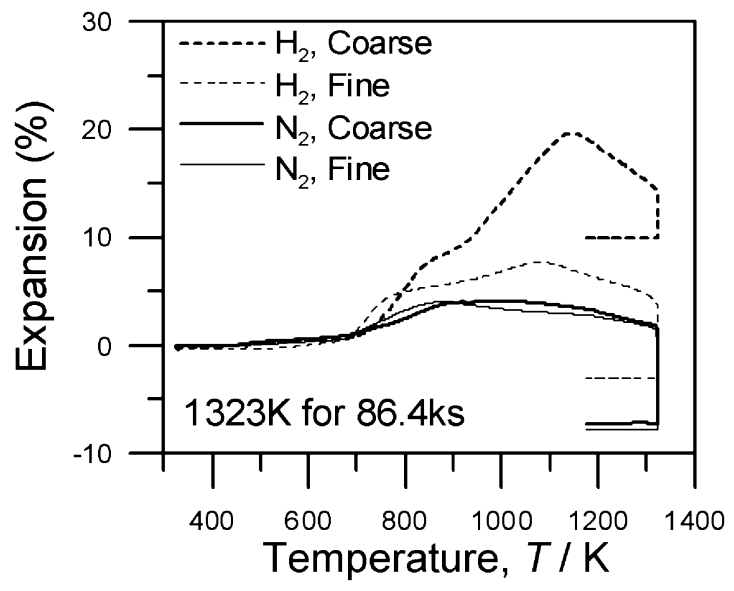

Fig. 4 Expansion of copper powder started between $673 \mathrm{~K}$ and $723 \mathrm{~K}$, and the coarse powder, which contained more oxygen, expanded more than the fine powder.

small amount of increase in volume calculated from the pycnometer density cannot explain the large amount of volume expansion of sintered compacts. Thus, to better understand the densification and swelling mechanism, the insitu dimensional changes during sintering were measured using a dilatometer. Figure 4 indicates that swelling of the coarse powders started at about $723 \mathrm{~K}$. As the temperature increased, the amount of swelling increased, reaching a maximum of about $20 \%$ at about $1133 \mathrm{~K}$ and then decreasing. When nitrogen was used, swelling still occurred, but to a lesser extent. The maximum amount of expansion was only about $4 \%$. However, this expansion was offset by the densification of the powder during sintering and a net shrinkage was obtained after sintering.

When fine powder was used for the dilatometer test, swelling in hydrogen atmosphere was also observed during heating, even though a net shrinkage was obtained after sintering. This suggests that the reaction between hydrogen and oxygen still occurred. The starting temperature for swelling decreased to about $673 \mathrm{~K}$, probably due to the shorter distance for hydrogen to diffuse into the fine powder. The maximum amount of expansion was about one third of that with coarse powders, because the fine powder had a low oxygen content of 0.193 mass\%. In addition, fine powders have high sinterability, the densification could negate the swelling effect, and even a small amount of shrinkage was 
obtained after sintering in hydrogen. When nitrogen was used, swelling still occurred during heating and the maximum amount of expansion was only about $4 \%$. But this expansion was offset by the sintering of powders and a net shrinkage resulted, similar to the sintering behavior of the coarse powder.

\subsection{Microstructure evolution \\ 3.4.1 Coarse powder}

To explain the dilatometer curves, the morphology of the coarse powder compacts removed during different stages of heating was examined. Figure 5 shows that as the compact was heated to $673 \mathrm{~K}$, the powder morphology did not change. But cracks were observed in compacts heated to $723 \mathrm{~K}$. This indicates that cracking occurred between these two temperatures and caused expansion in the dilatometer curve. As the temperature increased to $1133 \mathrm{~K}$, where the maximum amount of expansion was measured, large numbers of cracks were observed. As powders were further heated to $1323 \mathrm{~K}$ and sintered for $3.6 \mathrm{ks}$, neck growth between particles became obvious, and the number of cracks decreased. This suggests that healing of cracks occurred during high temperature sintering, since these cracks had small radii at the crack tips and large surface areas, which are the driving forces for sintering.

The cross-section of the coarse powders was also examined as shown in Fig. 6. The microstructural observations confirm that some cracks existed in the powder heated to $723 \mathrm{~K}$, along with internal pores, which were already present in the as-received condition. As the compact was heated to $1133 \mathrm{~K}$, where the amount of expansion reached the maximum, more cracks were observed. But only a few cracks were noticed after sintering. Most cracks were sintered into longitudinal pores.

After etching with $25 \%$ nitric acid, the microstructure of the powder heated to $1133 \mathrm{~K}$ was further examined at higher magnification, as shown in Fig. 7. Most pores and cracks were connected to grain boundaries. This is understandable, as grain boundaries are easier for hydrogen to diffuse through, compared to the matrix. As a result, more water vapor forms at grain boundaries.

When nitrogen was used, cracking still occurred, as shown in Fig. 8(a) of the coarse powder heated to $973 \mathrm{~K}$, which explained the expansion between $673 \mathrm{~K}$ and $973 \mathrm{~K}$ in the dilatometer curve. Since there was no hydrogen in the atmosphere, the expansion must have been caused by the thermal expansion of the trapped gas in isolated pores. After sintering, no cracks were observed and significant neck growth occurred, as shown in Fig. 8(b). Similar observations were also noted when coarse powder was sintered in vacuum.

\subsubsection{Fine powder}

When the fine powder was heated in hydrogen, cracking still occurred even though the fine powders contained much less oxygen, as shown in Fig. 9 of the compact heated to $1073 \mathrm{~K}$, where the maximum amount of swelling occurred. However, all cracks disappeared after sintering, and smooth powder surfaces with obvious necking among powders resulted. Thus, if the morphology of the final sintered powder is used to establish the swelling mechanism, the conclusion will be erroneous. (a)

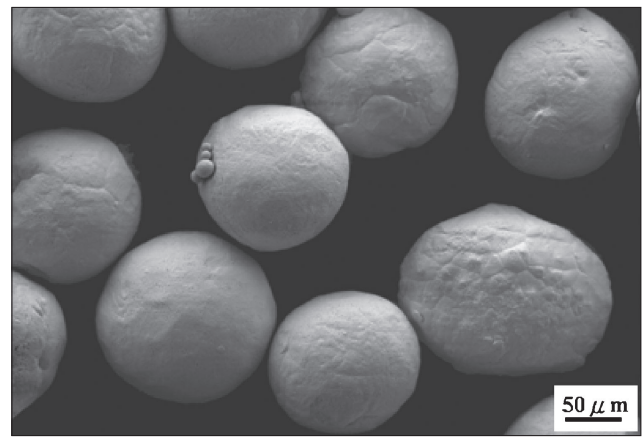

(b)

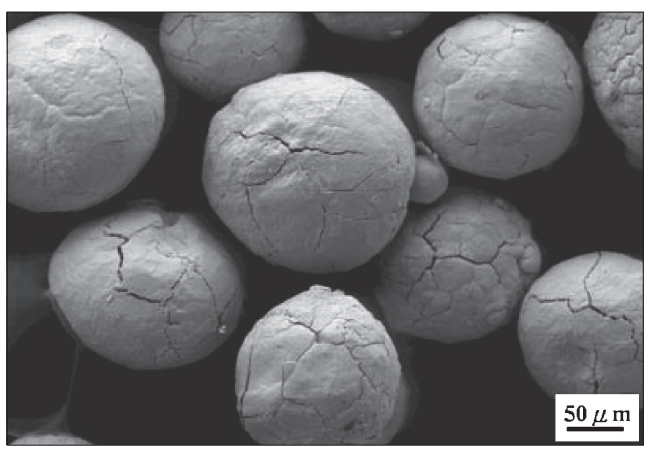

(c)

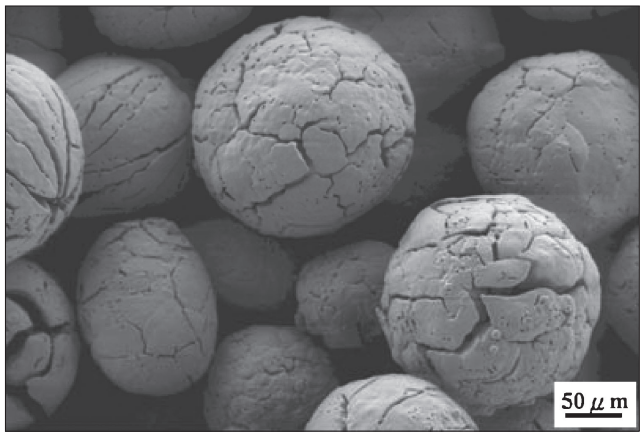

(d)

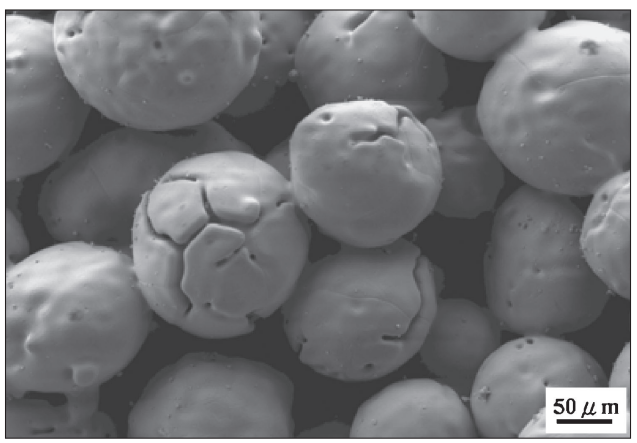

Fig. 5 The surface morphology of coarse copper powders heated in hydrogen to (a) $673 \mathrm{~K}$, (b) $723 \mathrm{~K}$, (c) $1133 \mathrm{~K}$, and (d) after sintering.

When sintered in nitrogen, the fine powder still cracked, as shown in Fig. 10(a) of the compact heated to $873 \mathrm{~K}$, where the amount of expansion saturated. But the extent of cracking was much less than that occurring in hydrogen and agreed with the amount of expansion observed in dilatometer curves. These small cracks were also healed after sintering, as shown in Fig. 10(b).

\section{Discussion}

Several swelling mechanisms have been reported for sintered copper powders, including expansion of trapped air 
(a)

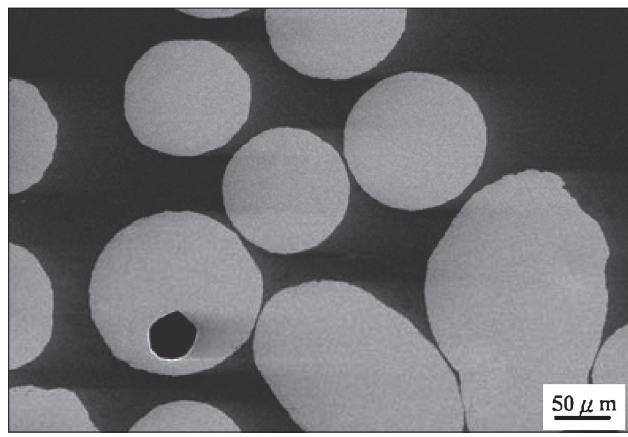

(b)

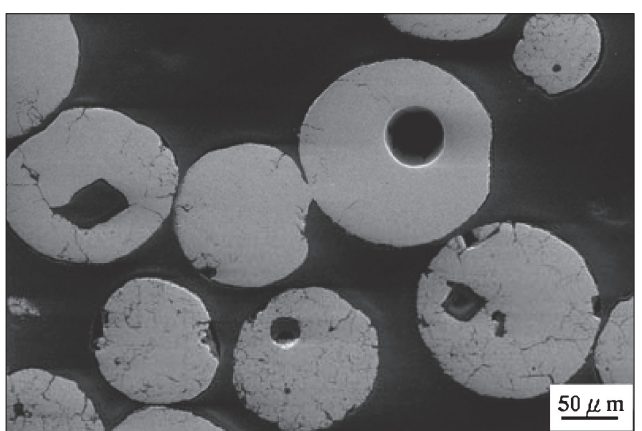

(c)

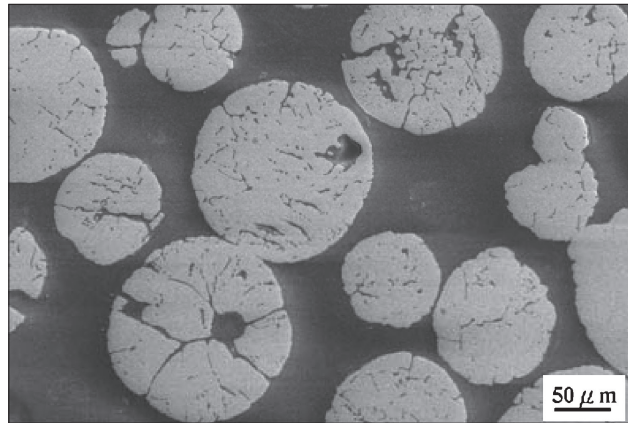

(d)



Fig. 6 The cross-section of coarse copper powders heated in hydrogen to (a) $673 \mathrm{~K}$, (b) $723 \mathrm{~K}$, (c) $1133 \mathrm{~K}$, and (d) after sintering.

closed-off during compaction, formation of hydrogen bubbles, and expansion of trapped steam. The expansion of compacts during sintering in nitrogen, as shown in Fig. 4 of the dilatometer curves and in Figs. 8(a) and 10(a), indicates that the expansion of trapped gas, which was in the asreceived powder, is one mechanism contributing to swelling during sintering of copper powder compacts. When the pressure of the trapped gas is high enough, cracking occurs, as shown in Fig. 8(a). When the pressure is too low to cause powder cracking, plastic deformation occurs and causes powder expansion. However, cracking and expansion by the originally trapped gas is not the main mechanism of copper

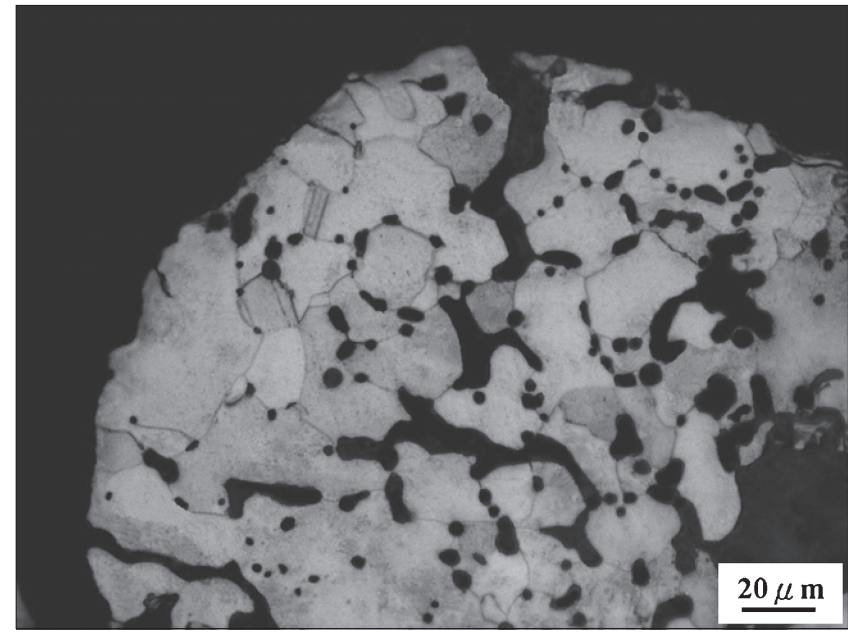

Fig. 7 The cross-section of coarse copper powders heated in hydrogen to $1133 \mathrm{~K}$.

(a)

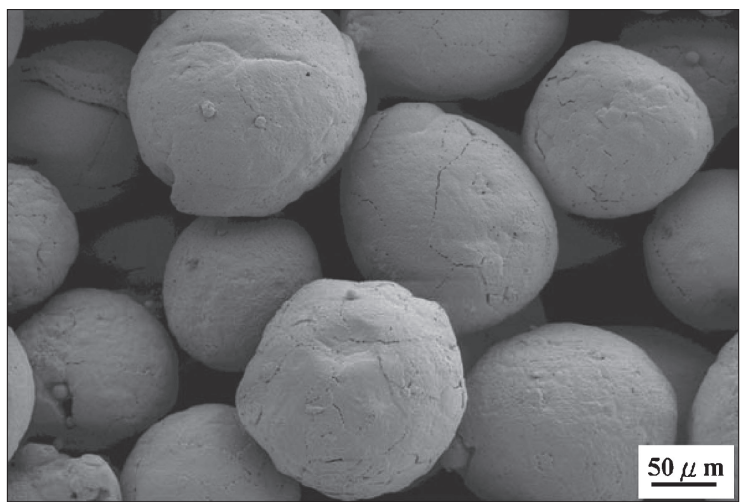

(b)

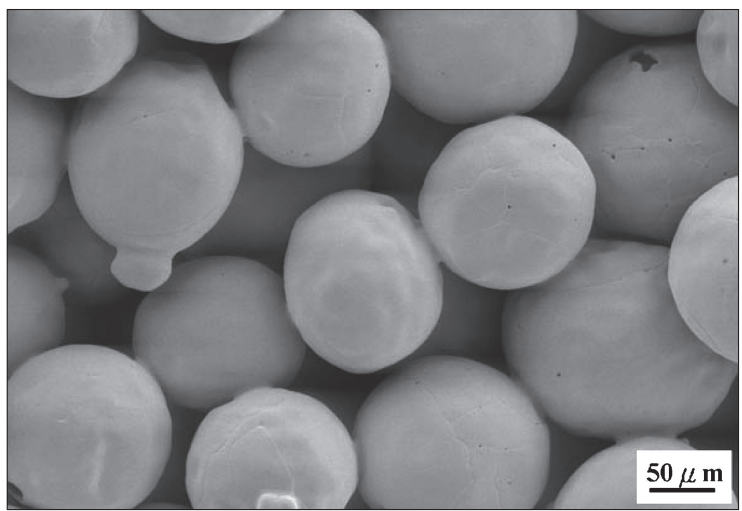

Fig. 8 The surface morphology of coarse copper powders (a) heated in nitrogen to $973 \mathrm{~K}$, and (b) after sintering.

powder swelling during sintering in hydrogen-containing atmosphere, for the amount of compact expansion in nitrogen is small. To determine whether hydrogen bubble formation is the key mechanism, sintered coarse powders were annealed at $423 \mathrm{~K}$ for $86.4 \mathrm{ks}$, following Nakahara's procedure. ${ }^{9)}$ The pycnometer density remained at $8.43 \times 10^{3} \mathrm{~kg} / \mathrm{m}^{3}$. This suggested that little hydrogen bubbles were present in the sintered powders and no hydrogen escaped during annealing. Since hydrogen bubbles are not the cause of swelling either, the most probable cause of copper powder swelling during sintering in hydrogen-containing atmosphere must be the reaction between hydrogen and oxygen. Since hydrogen has 
(a)
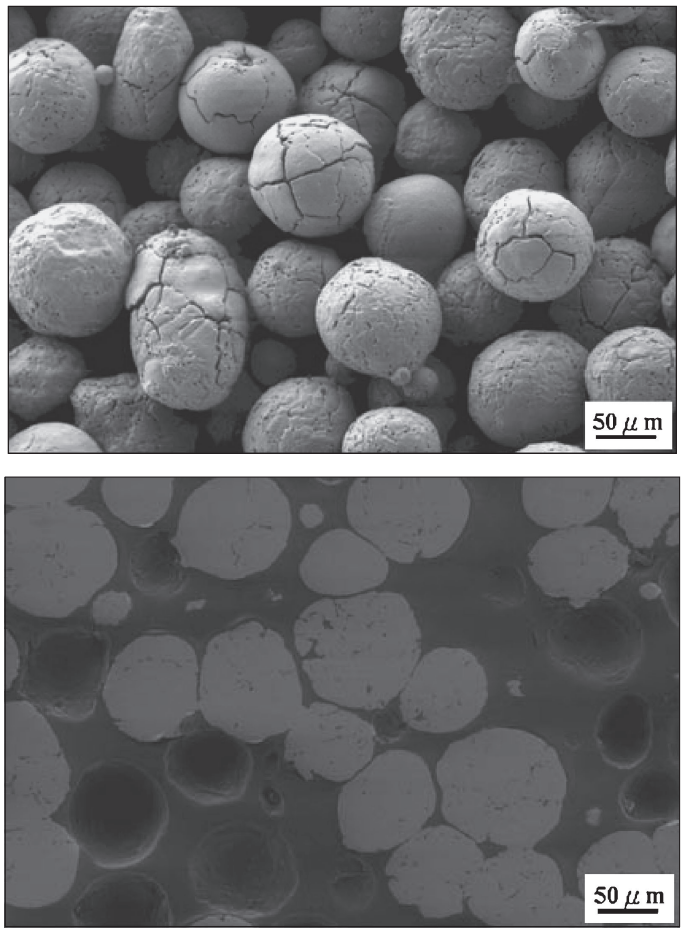

(b)
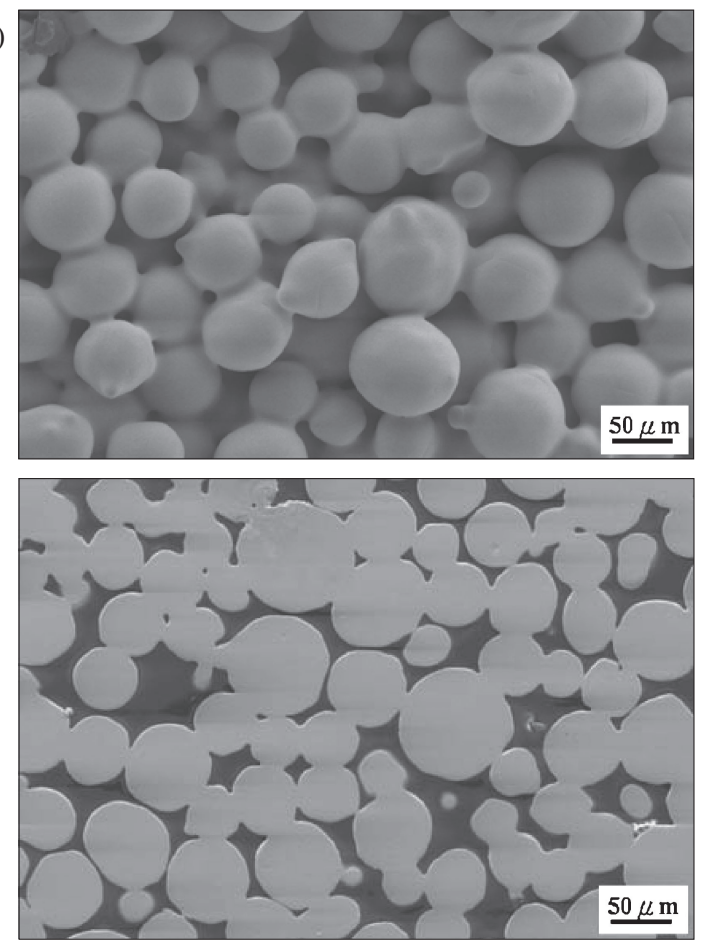

Fig. 9 The morphology and cross-section of fine copper powders (a) heated in hydrogen to $1073 \mathrm{~K}$ and (b) after sintering.

a fast diffusion rate into copper, ${ }^{19)}$ this reaction starts at a relatively low temperature of about $700 \mathrm{~K}$ and ends at about $1100 \mathrm{~K}$, as shown in Fig. 4, depending on the atmosphere, and the oxygen content and the particle size of the copper powder. This reaction could lead to swelling either by the plastic deformation caused by the expansion of the water vapor in isolated pores and grain boundaries or cracking of the powders. This swelling effect is somewhat negated above $1100 \mathrm{~K}$ due to the sintering effect of the powders and the healing effect of the fine cracks. (a)

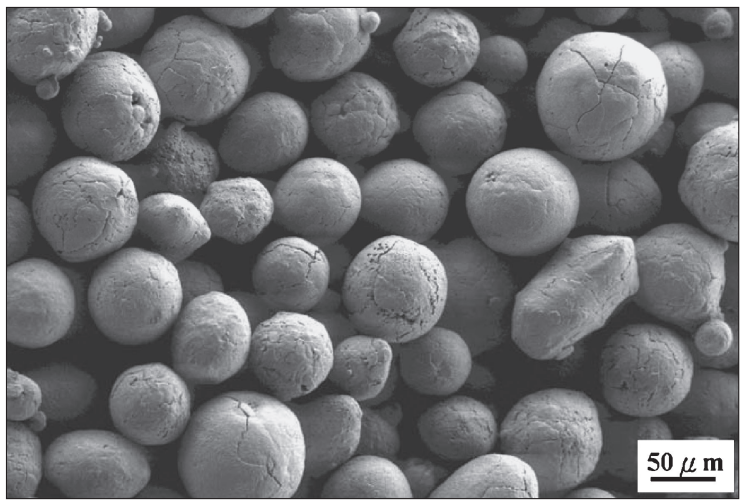

(b)

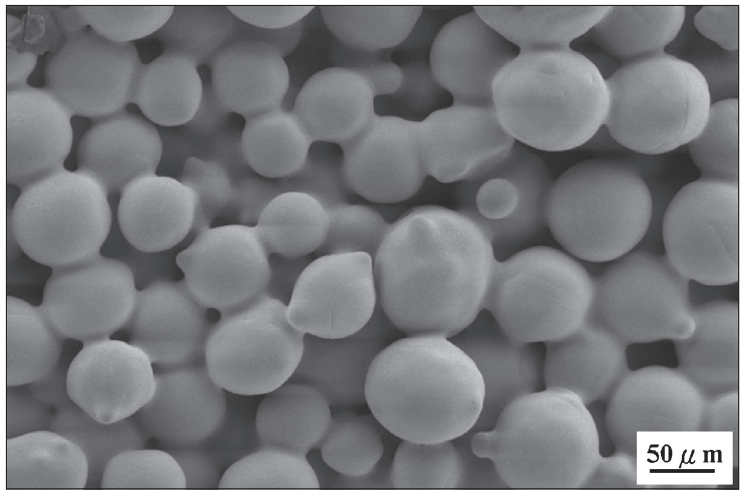

Fig. 10 The morphology of fine copper powders (a) heated in nitrogen to $873 \mathrm{~K}$ and (b) after sintering.

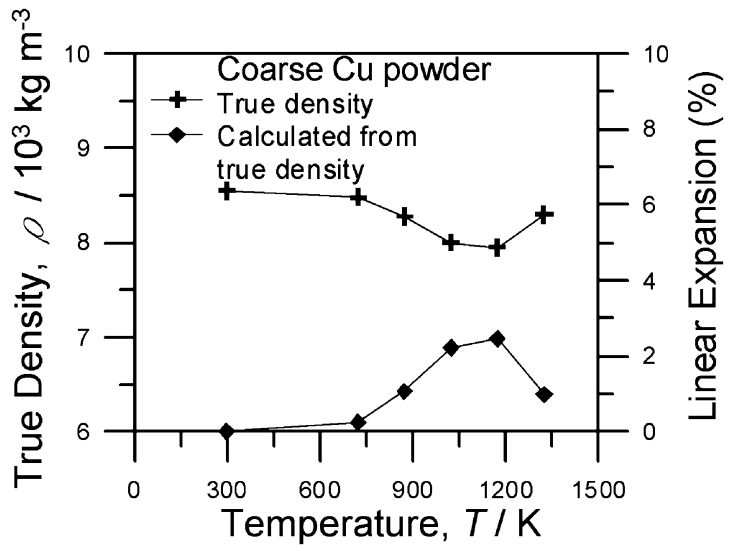

Fig. 11 The change in the pycnometer densities and corresponding linear expansion of sintered coarse powders follows the trend of the dilatometer curve.

The pycnometer densities of powders retrieved at different stages of heating in hydrogen, as shown in Fig. 11, demonstrate that the decreases in pycnometer density were small, and the calculated linear dimensional changes were quite small, compared to the dilatometer curves shown in Fig. 4. This suggests that the plastic deformation caused by the expansion of gas in isolated pores is not the main reason for the swelling of sintered copper powders. Instead, the cracking that occurred during heating, as shown in Figs. 5, 6, 7 , and 9 , is the major determinant of the swelling phenomena.

Coarse copper powders are generally preferred in heat pipe applications due to their high permeability and capillary speed. ${ }^{3)}$ However, coarse powder has little densification 
during sintering to offset the swelling. Considering the above results on density, microstructure, oxygen content, and dilatometer curves, it is recommended that when coarse powder is used in heat pipes, the oxygen content should be low to avoid problems with removing the core rod after sintering and to eliminate embrittlement problems during bending or flattening of sintered heat pipes. Moreover, as suggested from the density data in Table 2, the hydrogen content should be low to minimize the swelling effect, should a hydrogen-containing atmosphere be used. Based on the results obtained in this study, it is suggested to use copper powders with an oxygen content less than 0.2 mass $\%$ and to use an atmosphere with less than 5 vol\% hydrogen. The other alternative is to add oxygen getters such as chromium to form stable oxides, which are difficult to reduce by hydrogen at the sintering temperature. ${ }^{13)}$

\section{Conclusions}

Two copper powders with different mean particle sizes and oxygen contents were sintered in four different atmospheres to simulate the sintering of copper wicks in heat pipes. The effects of oxygen content and sintering atmosphere on the dimensional changes of sintered wicks were examined. The following are the concluding remarks:

(1) Copper powders with high oxygen content exhibit swelling after sintering in hydrogen-containing atmospheres. This is the main cause of difficulties in removing core rods from the sintering fixtures of heat pipes.

(2) Two swelling phenomena were observed and are related to the reaction between hydrogen in the atmosphere and the dissolved oxygen or oxides in the copper powder. The first one is cracking of individual powders, which is caused by the high-pressure steam in closed pores and at grain boundaries. The other mechanism is the plastic deformation when the steam pressure is not high enough to cause powder cracking. Similar effects also occur for powders sintered in nitrogen, but to a lesser extent, due to the originally entrapped gases in the as-received powder. The dilatometer curves and pycnometer densities indicate that cracking is the dominant swelling mechanism.
(3) Cracks that occurred during heating will be healed after sintering. For some powders, the sintering shrinkage can negate the swelling caused by hydrogen/oxygen reaction and still result in densification after sintering. Thus, the morphologies and dimensions of final sintered powders cannot be used to infer the swelling mechanism.

(4) The fine powder used in this study contained 0.193 mass $\%$ oxygen and a mean diameter of $55.7 \mu \mathrm{m}$ and it did not swell after sintering in hydrogen.

\section{REFERENCES}

1) A. Faghri: Heat Pipe Science and Technology, (Taylor and Francis, Washington, DC, 1995) pp. 3-9.

2) B. Holley and A. Faghri: Appl. Therm. Eng. 26 (2006) 448-462.

3) Y. J. Lin and K. S. Hwang: Metall. Mater. Trans. A 40A (2009) 20712078.

4) K. Hayashi, H. Asanuma and M. Itabashi: J. Jpn. Soc. Powder Powder Metall. 33 (1986) 22-27.

5) F. N. Rhines and W. A. Anderson: Trans. Metall. Soc. AIME 143 (1941) 312-325.

6) E. G. West: Copper and Its Alloys, (Ellis Horwood Ltd., New York, 1982) pp. 12-13.

7) T. J. Carter and L. A. Cornish: Eng. Fail. Anal. 8 (2001) 113-121.

8) E. Mattson and F. Schucker: J. Inst. Metals 87 (1959) 241-247.

9) S. Nakahara: Acta Metall. 36 (1988) 1669-1681.

10) F. V. Lenel: Powder Metallurgy Principles and Applications, (Metal Powder Federation Industries, Princeton, NJ, 1980) pp. 221-223.

11) K. Hayashi, T. W. Lin and M. Itabashi: Modern Developments in Powder Metallurgy, ed. by P. U. Gummeson and D. A. Gustafson, (Metal Powder Federation Industries, Princeton, NJ, 1998) pp. 287297.

12) H. Ito and K. Hayashi: Proc. 1993 Powder Metallurgy World Congress, Part 1, ed. by Y. Bando and K. Kosuge, (Japan Society of Powder and Powder Metallurgy, Kyoto, 1993) pp. 245-248.

13) V. A. Dymchenko and A. P. Popovich: Powder Metall. Met. Ceram. 22 (1983) 347-349.

14) K. Hayashi and H. Kihara: J. Jpn. Inst. Metals 50 (1986) 1089-1094.

15) J. F. Sweet, M. J. Dombroski and A. Lawley: Int. J. Powder Metall. 28 (1992) 41-51.

16) K. Hayashi, T. W. Lim and H. Komine: J. Jpn. Inst. Metals 53 (1989) $608-613$.

17) C. B. Jordan and P. Duwez: Trans. Metall. Soc. AIME 185 (1949) 96-99.

18) Y. J. Lin and K. S. Hwang: Mater. Trans. 50 (2009) 2427-2434.

19) L. Katz, M. Guinan and R. J. Borg: Phys. Rev. B 4 (1971) 330-341. 